Report No.

ER-B-91-18
U.S. Department of Hnergy

Office of Inspector General
Release Date:

August 28, 1991

Report on

Contract Administration

Involving the Remedial

Investigation and Feasibility

Study at the Feed Materials

Production Center

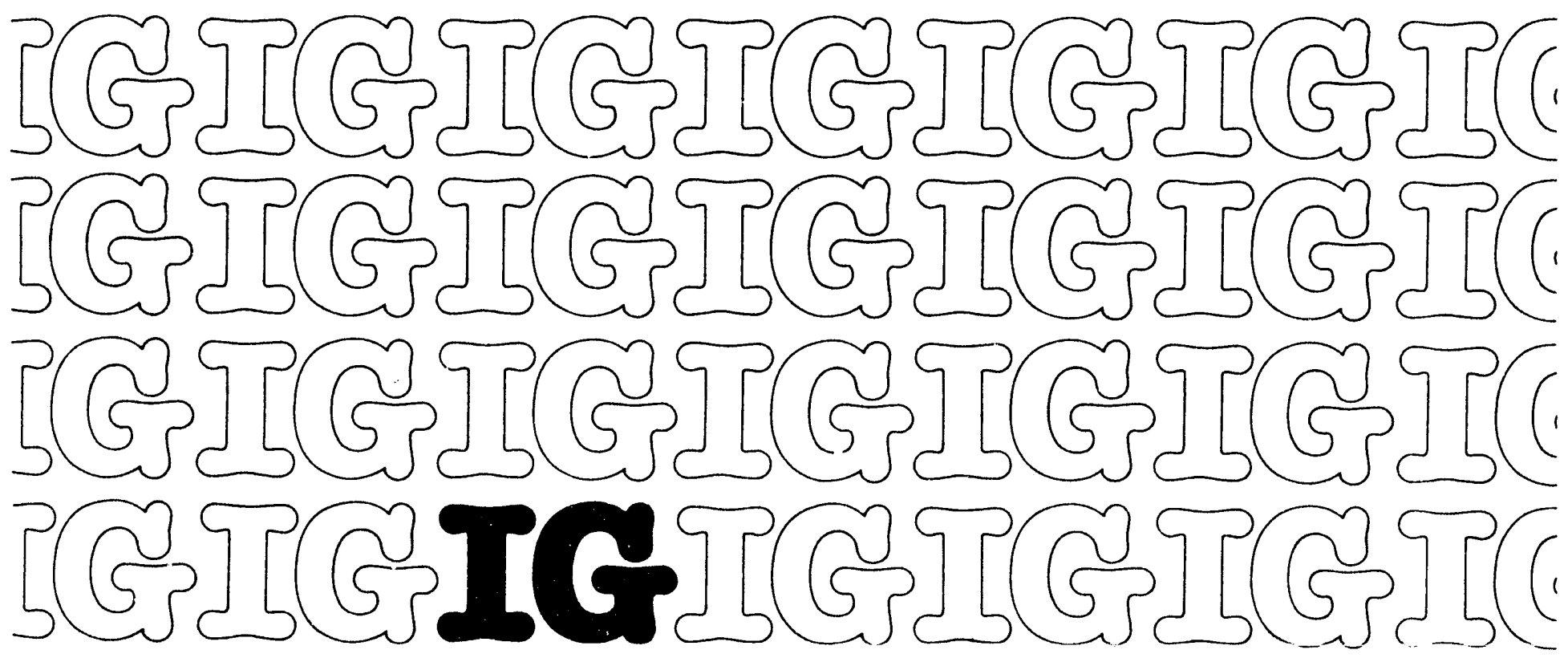


This report can be obtained from the U.S. Department of Energy Office of Scientific and Technical Information P. O. Box 62

Oak Ridge, Tennessee 37831 


\section{CONTRACT ADMINISTRATION \\ INVOLVING THE REMEDIAL INVESTIGATION AND \\ FEASIBILITY STUDY AT THE FEED MATERIALS \\ PRODUCTION CENTER}

TABLE OF CONTENTS

Page

SUMMARY $\ldots \ldots \ldots \ldots \ldots \ldots \ldots \ldots \ldots \ldots \ldots \ldots \ldots \ldots \ldots$

PART I - APPROACH AND OVERVIEN $\ldots \ldots \ldots \ldots \ldots \ldots \ldots \ldots \ldots \ldots \ldots$

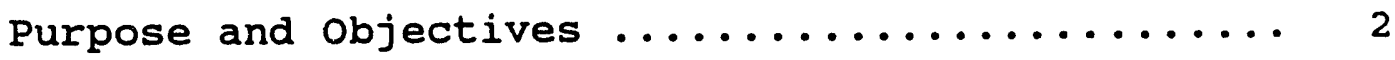

scope and Methodology ................... 2

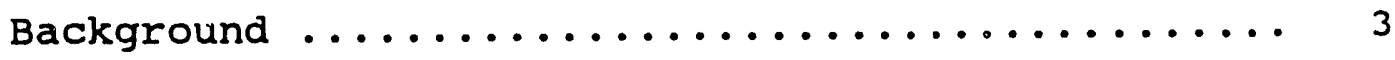

Observations and conclusions .............. 5

PART II - FINDINGS AND RECOMMENDATIONS ............. 7

PART III - MANAGEMENT AND AUDITOR COMMENTS ........... 19 


\section{U.S. DEPARTMENT OF ENERGY \\ OFFICE OF INSPECTOR GENERAL OFFICE OF AUDITS}

CONTRACT ADMINISTRATION

INVOLVING THE REMEDIAL INVESTIGATION AND

FEASIBILITY STUDY AT THE FEED MATERIALS

PRODUCTION CENTER

Audit Report Number: ER-B-91-18

August 28, 1991

\section{SUMMARY}

Advanced Sciences, Incorporated (ASI), has been performing a Remedial Investigation and Feasibility study (RI/FS) at the Feed Materials Production Center (Fernald Facility) at Fernald, Ohio, under an 8 (a) contract with the U.S. Small Business Administration (SBA). The Fernald Facility is a Government-owned facility operated by Westinghouse Materials Company of ohio (WMCO) under a management and operating contract. The objective of this audit was to evaluate the award and administration of the ASI contract.

our audit disclosed that the selected contractor was not qualified to perform an extremely complex RI/FS such as at the Fernald Facility, and that the contract was not always properly administered. These conditions could have contributed to cost growth and the recent assessment of penalties for failure to timely complete the study. Moreover, because of these conditions, the U.S. Department of Energy (DOE) had limited assurance that the work had been accomplished in accordance with the contract. We recommend seven steps for improving contract administration.

Management generally agreed with the recommendations in the report and is taking corrective actions.

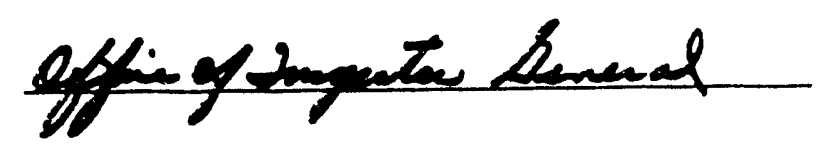




\section{PART I}

\section{APPROACH AND OVERVIEW}

\section{PURPOSE AND OBJECTIVES}

The purpose of the audit was to review the award and contract administration functions by DOE and WMCO.

The specific objective was to evaluate the award and administration of the Remedial Investigation and Feasibility study (RI/FS) contract with Advanced Sciences, Incorporated (ASI), at the Fernald Facility. 1/

\section{SCOPE AND METHODOLOGY}

We reviewed the award and administration of the RI/FS contract with ASI at the Fernald Facility from November 1990 to January 1991.2/ The audit covered the period from the ASI coniract award on July 18, 1986, through January 1991. It included: (1) Discussions with the small Business Administration (SBA), Environmental protection Agency (EPA), DOE's Oak Ridge Field office (OR), and present and former wMCo personnel; (2) review of contract administration files; and (3) review of the contract, contract modifications, and supperting files.

The audit was made in accordance with generally accepted Government auditing standards for performance audits, and included tests of internal controls and compliance with laws and regulations to the extent necessary to satisfy the audit objectives. We assessed internal controls in the areas of selecting a contractor, administering the contract and monitoring contractor performance to assure that goals stated in the contract were met. With respect to compliance testing, we used as criteria the Federal Acquisition Regulations (FAR), the DOE Procurement Regulations (DEAR), the DOE/WMCO contract, and the ASI contract. Because our review was limited, it would not necessarily disclose all. internal control deficiencies that may have existed.

1/ A RI/FS has two distinct but related studies, usually performed at the same time. The RI/FS is intended to (1) gather the data necessary to determine type and extent of contamination; and (2) identify and screen cleanup alternatives for remedial action and analyze the technology and costs of the alternatives.

2/ Information with respect to assessment of penalties by EPA was obtained in June 1991. 
We discussed our findings with management during a telephonic exit conference on August 21, 1991.

\section{BACKGROUND}

WMCO manages, operates, and maintains the Fernald Facility for DOE under a cost-plus-award fee contract (No. DE-AC05-860R21600) administered by OR until March 1991, at which time DOE transferred certain oversight responsibilities from OR to the Office of Environmental Restoration, Division of Eastern Area Programs. The Fernald Facility has discontinued production and is performing environmental remediation. WMCO employs 1,000 people and has an annual operating budget of $\$ 220$ million.

DOE delegated most of the responsibilities for administering the ASI contract to WMCO. However, the DOE contracting officer has ultimate responsibility for contract administration in accordance with Federal Acquisition Regulations (FAR).

The current arrangement for administering the RI/FS has developed in steps over the past 5 years.

- DOE and EPA signed the Federal Facilities Compliance Agreement (FFCA) on July 18, 1986. This action was the first step toward environmental cleanup of the Fernald Facility.

- DOE signed a contract with SBA on the same day to accomplish the statement of work identified in the FFCA.

- To perform the RI/FS, SBA subcontracted with ASI, an eligible $8(a)$ concern pursuant to the provisions of section 8 (a) of the Small Business Act as amended by 15 USC 637 (a). 3 / This contract's period was 1 year with 4 option years.

- SBA delegated to DOE the responsibility for administering the ASI subcontract, affording DOE complete authority to take any action on behalf of SBA under the terms and conditions of the contract.

- DOE in turn delegated most of the ASI contract administration responsibilities to WMCO.

3/ Section 8 (a) of the small Business Act provides for noncompetitive award of contracts through the SBA to minority-owned businesses in order to enhance their ability to obtain Government business competitively. 
DOE designated WMCO as contracting officer's Representative (COR) in JulY 1986 . DOE resumed COR responsibility in August 1987 , consistent with the requirements of DOE Draft order 5400 .YY. However, DOE left the contract administration responsibilities with WMCO, as originally delegated.

Modification 49 of the SBA/ASI contract, dated March 29 , 1990, extended the RI/FS completion date from July 1990 to september 1992 and exercised the fourth option period to meet the revised date. This action brought the total ASI performance period to 6 years and 2 months. Since ASI is no longer eligible for new awards under the 8 (a) program, the existing SBA/ASI contract cannot be further extended.

- DOE changed the contract's reporting requirement to an operable-unit concept rather than a task-order concept on April 17, 1989, to better measure cost and performance against established milestones.

- DOE and EPA renegotiated the FFCA on June 29, 1990, because they considered the original agreement ineffective. The renegotiated agreement established penalties that EPA could assess if deliverables were not timely.

The ASI contract has escalated from the original estimates of $\$ 1.7$ million to the current estimated completion cost of $\$ 72$ milition for the following reasons.

- The original estimate of $\$ 1.7$ million was unrealistic, because it was based on the assumption that ASI could take another company's previously generated workplan for a specific area at the Fernald Facility and make minor changes to accomplish the work required under the FFCA for the entire Fernald Facility.

- Modifications of $\$ 8.3 \mathrm{million}$ were added to the contract soon after the initial award to fund support-type functions that required additional level of effort not included in the initial scope of work.

- Modifications of $\$ 62$ million were added to the contract between May 1988 and september 1990. Some of the modifications specifically stated that the funding was being added due to changes in technical directions.

- ASI, DOE, and WMCO were inexperienced with the RI/FS process. 
On August 23, 1991, the name of the Fernald Facility was changed to "Fernald Environmental Management Project," and WMCO's name was changed to "Westinghouse Environmental Management Company of Ohio."

\section{OBSERVATIONS AND CONCLUSIONS}

The contract was awarded to an unqualified contractor and was not always administered in a manner that assured compliance with contract terms and the safeguard of Government interests. specific problems were as follows.

- DOE did not assure the award of the RI/FS contract to a qualified contractor.

- The DOE contracting officer did not ensure and the WMCO contracting administration office did not adequately document ASI's performance.

- During the period of January 1989 through February 1990, WMCO paid ASI invoices totalling $\$ 15,977,157$ that the DOE COR had not reviewed.

- SBA signed the original ASI contract without the designation of key ASI personnel, and ASI subsequently changed the project manager without notifying WMCO and DOE.

- ASI modified subcontracts without notifying the contracting officer in advance or receiving the contracting officer's consent.

- ASI did not meet the SBA's 55-percent labor requirement in the first year, and without adequate data there is no assurance that ASI will meet this requirement during the entire contract period.

- ASI did not always submit reports that were useful in determining if the cost and performance objectives were being met.

- Contract modifications were not always definitized timely (within 180 days).

We recommend seven steps for improving contract administration. Part II contains details of these observations, along with appropriate recommendations. 
our finding identifies internal control weaknesses that DOE should consider when preparing its yearend assurance memorandum on internal control.

6 
PART II

FINDINGS AND RECOMMENDATIONS

Award and Administration of the study

\section{FINDING}

The SBA/ASI contract clauses and the Federal Acquisition Regulations (FAR) provisions identify specific rules and regulations that contracting officers must follow in order to award and administer contracts properly. However, the SBA/ASI contract was not awarded or administered properly in all respects. This condition occurred because (1) The contractor that DOE selected was not qualified because of its lack of experience in performing a RI/FS of the magnitude at Fernald; and (2) DOE delegated most of the contract administration responsibility to WMCO, which was not an effective arrangement. As a result, there likely was unnecessary cost growth, DOE had limited assurance that the work would be accomplished timely and in accordance with the contract, and penalties were assessed for delays in completing the study.

\section{RECOMMENDATION}

We recommend that the Acting Director, Eastern Area Program Division, DOE Office of Environmental Restoration, implement the following corrective actions through the DOE contracting officer.

1. Withdraw delegation of contract administration from WMCO;

2. Delegate future contract administration responsibilities only when it provides a high probability of success, and ensure that the delegation be accompanied with commensurate authority to act on the Government's behalf;

3. DOE consent to SBA's awarding of future DOE-related contracts to 8 (a) firms only when DOE possesses the experience and expertise to adequately guide the $8(a)$ firm's performance;

4. Instruct the DOE COR to review and approve or reject a 1 l unapproved ASI invoices and request the contracting officer to seek restitution from ASI for any unapproved payments; 
5. Monitor ASI's participation to assure that the 55-percent labor requirement is met consistently with SBA guidelines;

6. Assure that the new cost and performance system appropriately tracks the RI/FS project; and

7. Assure that contract modifications are definitized timely (within 180 days).

\section{MANAGEMENT REACTION}

DOE's Office of Environmental Restoration generally agreed with the finding and recommendations. Part III contains details.

\section{DETAILS OF FINDING}

\section{Contracting Officer's Responsibilities}

The FAR and the implementing Department of Energy Acquisition Regulations (DEAR) provide that contracting officers are responsible for (1) selecting a contractor, (2) ensuring performance of all necessary actions for effective contracting, (3) ensuring compliance with the terms of the contract, and (4) safeguarding the interest of the United States in its contractual relationships. The contracting officer's responsibilities include an array of activities such as awarding contracts to a qualified contractors, administering contracts efficiently, and managing contracts to assure that Governments assets are safeguarded. The regulations further provide that contract administration functions may be delegated.

This guidance and the terms of the contract must be followed in order to award and administer the contract properly.

\section{Contracting officer's Performance Could Be Improved}

The performance of the DOE, ASI contracting officer responsibilities could be improved with respect to award of the contract and administration in a manner that assured compliance with contract terms and the safeguard of Government interests. Specific problems areas were:
- Selecting a contractor,
- Documenting the contract files, 

- Reviewing ASI invoices,
- Monitoring key personnel,
- Approving subcontracts,
- Allocating work between contractor and subcontractor,
- Monitoring cost and performance, and
- Definitizing contract modifications.

\section{Selecting a contractor}

Federal Acquisition Regulations provide specific guidance for selecting contractors.

0

FAR 19.801 (b) (1) states: "When, acting under the authority of the program, the SBA certifies to an agency that the SBA is competent and responsible to parform a specific contract, the contracting officer is authorized, in the contracting officer's discretion, to award the contract to SBA based upon mutualiy agreeable terms and conditions."

- FAR 19.810 (c), "Contract Administration," states: "To the extent consistent with the awarding agency's capability and resources, SBA contractors furnishing requirements shall be afforded production and technical assistance, including, when appropriate, identification of causes of deficiencies in their products and suggested corrective action to make such products acceptable."

This guidance must be followed in order to award the contract properly.

Notwithstanding this guidance, the contractor that DOE and SBA selected was not qualified because of its lack of experience in performing a RI/FS of the magnitude at Fernald. Since the RI/FS $a^{2}$ Fernald was the largest of its kind performed within DOE, all parties involved in this process were relatively inexperienced. AsI did not possess the staff or the expertise to develop a RI/FS workplan and coordinate the RI/FS activities at Fernald. Although SBA believed that ASI possessed adequate competence to perform the study, DOE did not use proper discretion by allowing an inexperienced contractor to perform a relatively unfamiliar scope of work. Because both DOE and WMCO were inexperienced 
and unfamiliar with the RI/FS process, thay were unable to provide ASI the assistance and expertise normally provided to 8 (a) contiactors.

\section{Documenting the contract Files}

Federal Acquisition Regulations provide specific guidance for establishing ard maintaining contract files.

- FAR 4.801 (a), "General," requires: "The head of each office performing contracting, contract administration, or paying functions shall establish files containing the records of all contractual actions." FAR 4.8.1 (b) requires: "The documentation in the files shall be sufficient to constitute a complete history of the transaction for the purpose of providing a complete background as a basis for informed decisions at each step in the acquisitioil process."

- FAR 4.803 (b) (1), "Contents of Contract Files," states that the contract files should include a "Copy of the contract and all modifications, together with official record copies of supporting documents executed by the contract administration office."

- FAR 4.803 (b) (19) states tilat the contract files should also include "any additional documents on which action was taken or that reflect actions by the contract administration office pertinent to the contract."

This guidance must be followed in order to administer the contract properly.

However, wMCo's contracting administration office did not adequately document the contract files to provide support of ASI's performance. Specifically, bo'ch the WMCO contract administrator and the WMCO COR stated that a wide array of performance problems occurred and that they tried to convince DOE to have SBA terminate the ASI contract. For example:

- The 30-day draft report due on August 8, 1986 required extensive revisions by the WMco staff before it could be submitted to DoE. Specifically, wMCO reviewed ASI's geohydrological and geophysical sampling plans of the workplan on August 25, 1986, and found it poorly conceived and generally not workable. WMCO directed ASI to 
rework the plan. ASI submitted the revised plan again in september, and WMCO again determined the plan to be nonworkable. At that point, wMCo suggested to ASI that it replace one of its subcontractors with a more technically competent firm.

○

The 60-day draft report that ASI submitted on September 4, 1986, required extensive revisions by the WMCO Environmental compliance staff. on September 25, 1986, WMCO met with DOE to discuss ASI's management of the study to date. DOE conveyed WMCO's concerns to ASI.

- The 90-day workplan, due to DOE on october 10 , 1986 , was submitted on December 17 , 1986. On December 19,1986 , DOE transmitted it to EPA, who determined it unacceptable.

However, the contract files did not show that these problems existed. By not documenting such problems with ASI, WMCO personnel believed they were complying with DOE's wishes to make the contract work. Thus, the files contain inadequate documentation of the cost, schedule, and performance problems WMCO encountered with ASI.

We were advised that the contract files were being adequately documented at the time of this audit.

\section{Reviewing ASI Invoices}

DOE's COR Responsibility Delegation Letter states that the COR will "review contractor's period billings or vouchers in relation to the contract and progress reports to determine whether work accomplished is commensurate to payment requested and process vouchers for payment."

Accordingly, WMco's normal practice was as follows.

- ASI would submit an invoice to the WMCO senior contract administrator every 2 weeks for reimbursement.

- The senior administrator reviewed the invoice to assure the indirect rates and the direct labor rates were in accordance with those negotiated under the provisional rate agreement between DOE and ASI. The senior administrator would also submit the invoice to the DOE COR for a technical review to assure the reasonableness of the costs in relation to the work scope requirements under the contract. Concurrence signatures of both the 
contract administrator and the DOE COR on an internal voucher routing sheet indicate the costs are reasonable and acceptable in relation to the requirements of the work scope and the contract terms and conditions.

- WMCO would then reimburse ASI based on the approved invoice.

DOE COR must review the invoices to ensure that work accomplished is commensurate to payment requested.

However, during the period of January 1989 through February 1990, WMCO paid invoices before the DOE COR reviewed them. The WMCO contract administrator sent the invoices to the DOE COR and waited for approval. The WMCO contract admiristrator stated that after numerous attempts to obtain tyese written confirmations, she requested unofficial reviews from the WMCO technical monitor in order to obtain some basis for technical reasonableness of the costs. These reviews were unofficial because the technical monitor had responsibility for the day-to-day operation but no authority to approve invoices. Based on these reviews, payment to ASI continued with DOE's knowledge to assure that ASI's work continued and to prevent ASI's financial collapse (ASI was using a bank line of credit, and any delay of reimbursement would deplete the line of credit). However, the invoices submitted during January 1989 through March 1990 remain unsigned by the COR. Thus, DOE has no technical assurance that the work accomplished was commensurate with the payment requested and received.

The DOE contracting officer instructed WMCO in February 1990 not to pay any further invoices until receiving concurrence from the DOE COR. As of March 1990, the payment without COR approval had been corrected.

\section{Monitoring Key Personnel}

Contract clause H.005 states: "The clause entitled 'Key Personnel' contains a requirement for notification to the co [contract officer] reasonably in advance of diverting of, or substitution for, any of these individuals. That period of time shall not be less than thirty (30) days."

Nonetheless, the contract requirements with respect to key personnel were not always performed. Specifically, SBA signed the original contract without the designation of key personnel. Additionally, ASI changed the project manager (a key person) without notifying WMCO or DOE. 
Thus, DOE had no assurance that ASI was providing competent key personnel to assure that cost, scheduling, and performance requirements were being met under the contract.

ASI was complying with the contract requirements with respect to key personnel at the time of this audit.

\section{Approving Subcontracts}

Two documents provide guidance on approving subcontracts.

- Contract clause H.006 A(3) states that the Contractor shall ensure that any required prior notice and description of the subcontract is given to the $C O$ and any required consent is received. This requirement includes modifications to subcontracts initially approved.

- FAR 44.102 (a), "Policy," states: "Consent to subcontract is required under 44.201 when the subcontract work is complex, the dollar value is substantial, or the Government's interest is not adequately protected by competition and the type of prime contract or subcontract. (b), consent requirements may be waived when the contractor's purchasing system has been reviewed and approved in accordance with subpart $44.3 . "$

This guidance must be followed in order to administer the contract properly.

To the contrary: (1) ASI modified subcontracts without notifying the contracting officer in advance or receiving the contracting officer's consent, and (2) DOE and WMCO did not review and approve ASI's procurement system to allow consent requirements to be waived.

- Notifying the contracting officer. Without notifying the contracting officer in advance or receiving DOE's consent, ASI modified three subcontracts that DOE had initially approved. ASI assumel that its prime contract negotiation with SBA aljowed them to modify their subcontracts. WMCO initially allowed these events to occur based on the DOE contract specialist's oral guidance. The WMCO contract administrator later questioned ASI's compliance with the modifications. As a result, DOE reversed its earlier oral guidance by 
requiring in a procurement authority letter dated December 20, 1989, that advanced notification and consent be submitted on subcontract modifications in accordance with the SBA/ASI contract clause.

- Reviewing and Approving ASI's Procurement System. DOE and WMCO did not review and approve ASI's procurement system to allow waiver of requirements for consent to modify subcontracts. Although DOE performed a procurement review in January 1990 ( 3.5 years after the contract award), this review could not be used as a basis for waiving earlier subcontract modifications.

Although these matters have been corrected, ASI executed subcontract modifications for approximately 3.5 years without the required DOE notification and consent that would have better assured contract performance.

\section{Allocating work Between Contractor and Subcontractor}

The SBA requires potential 8 (a) contractors to sign an agreement stating that for professional and nonprofessional service contracts, at least 55 percent of the total labor cost - including subcontracts - must be expended by employees of the 8 (a) concern.

An SBA representative stated that an 8 (a) contractor must meet the 55-percent requirement every year of an option-year contract unless the contracting officer establishes a guaranteed minimum period of performance. However, the former small business specialist at OR stated they did not guarantee 8 (a) contractors a minimum period of performance because they wanted them to work hard enough to earn the option years.

Nevertheless, we were told that ASI did not meet the 55-percent requirement in the first year, and WMCO cannot assure DOE that ASI has met the requirement since the beginning of the contract. We were unable to determine compliance with the 55-percent requirement after the first year, because ASI never submitted the required data to WMCO. Furthermore, WMCO did not require ASI to submit data periodically to assure that the proper labor relationship was being maintained or would be achieved.

In May 1988, WMCO calculated the percentage of ASI's labor contribution based on costs projected through the end of the contract and determined that ASI could meet SBA's 55-percent requirement by the contract completion date. However, this calculation did not comply with the SBA requirement, in that: (1) WMCO excluded subcontract labor 
costs of two subcontractors from the denominator it used to calculate the ASI projected percentage; and (2) the subject period should have been on a year-to-year basis, not by the contract completion date. Since a calculation on a total contract period basis is not permitted, we did not recalculate the projected percentage.

If ASI does not contribute to the effort as required by SBA, the 8 (a) program objectives may not be achieved.

\section{Monitoring cost and Performance}

The following standards provide DOE and WMCO guidance for monitoring contract cost and performance.

- Contract Clause H.028 states, "The contractor shall prepare and submit the plans and reports indicated on the attached DOE F 1332.1, Reporting Requirements Checklist."

- DOE F 1332.1, "Reporting Requirements Checklist" under item 4.A. requires that ASI submit a quarterly Cost Management Plan.

- Good business practices require that an adequate cost management plan provide detailed progress reports, milestones, budgets, and a cost account plan. The detailed schedules and cost account plans are necessary to:

- Track the RI/FS contractor's cost versus schedule performance;

- Determine if objectives are achievable within budget and schedule constraints;

- Determine the impacts on costs and schedules due to EPA requests, RI/FS progressive findings, or problems encountered in the field; and

- Provide a degree of assurance that commitments to regulatory agencies will be met.

This guidance should be followed to ensure adequate measurement of contractor performance.

Even though the reports submitted by ASI complied with the contract, the initial reports did not provide an adequate measurement of contractor performance. In the beginning, reports were based on task orders, as required by 
the contract. However, DOE stated that these reports were not an adequate basis to measure the cost and performance objectives, since a task order included many different areas of the Fersald Facility. DOE changed ASI's reporting requirements in early 1990, and at the time of our audit, ASI was submitting detailed cost and performance reports based on operable units. These reports include budgeted versus actual costs and budgeted versus actual milestone completion dates. Although the revised reporting system provides an adequate basis to track performance, ASI performed about 4 years of the contract without adequate reports to monitor the contractor's performance.

\section{Definitizing Contract Modifications}

Two documents provide guidance on definitizing contract modifications.

- DEAR 916.603-2 (c) (d) states: "In accordance with FAR 16.603-2(c), a letter contract shall provide for definitization of the contract not more than 180 days after the date of the award or after completion of 40 percent of the work to be performed, whichever occurs first, unless approved in advance by the Procurement Executive."

- The FAR 43.204 (b) "Definitization," states: "Contracting officers shall negotiate equitable adjustments resulting from change orders in the shortest practicable time."

This guidance must be followed in order to administer the contract properly.

Based on the regulation governing the letter contract, we define the term "shortest practicable time" for change orders as being not more than 180 days, as required for definitizing letter contracts.

However, based on a review of the contract modifications, 9 of the 52 ASI contract modifications exceed the 180-day limit by 8 to 117 days. These nine modifications were change orders that exceeded the 180-day limit. In many cases, a technical change would occur and DOE would issue a change order that allowed ASI to continue working to avoid the stop-and-start-up expenses. The technical changes contained in the change orders were then negotiated and definitized in a contract modification. 
Contract selection and Delegation of contracting officer's Responsibilities Was Not Effective

The conditions identified herein occurred principally because: (1) The contractor that DOE and SBA selected was not qualified to perform a RI/FS of the magnitude at the Fernald Facility, and (2) DOE delegated most of the contract administration responsibility to WMCO, which was not an effective arrangement.

DOE needed an experienced contractor for a RI/FS of the magnitude and complexity at the Fernald Facility, but ASI was inexperienced and therefore unqualified. Under the SBA's 8 (a) program, contractors are usually new and inexperienced in contracting with the Government. Accordingly, the agency consenting to the SBA's contractor normally provides technical assistance and expertise. However, DOE and WMCO could not provide ASI technical assistance, because they were inexperience in the RI/FS process, themselves.

DOE's delegation of most contract administration responsibilities to WMCO were ineffective for the following reasons.

- WMCO had Iimited experience to carry out the RI/FS administration responsibility in both the technical and contract administration areas.

- The roles of responsibility and authority were unclear. The DOE COR and the WMCO contract administrator were answerable to the DOE $\mathrm{CO}$, while WMCO was answerable to the DOE site manager (who was also the DOE COR for the ASI contract). This arrangement resulted in WMCO's having most of the administrative responsibility for the ASI contract but very little authority to ensure ASI'S performance.

- WMco's contract administrator told us that a DOE official said that if ASI fails, WMCO fails, a statement that caused WMCO personnel to place less emphasis on contract administration functions by not documenting problems with ASI performance, and that further confused the lines of authority and responsibility.

- WMCO did not follow all established internal contruls, such as review of invoices, monitoring procurement practices, and monitoring costs and performance. 
successful and pimely Completion of the study in Accordance with the Contract was Not Assured, and Delay Penalties Were Assessed

As a result of the conditions identified herein, there likely was unnecessary cost growth (see Background section). Also, DOE had limited assurance ASI was accomplishing the work in accordance with the contract, specifically whether:

- WMCO's contract administration files were being appropriately documented to include an accurate history of ASI's performance;

- All ASI's costs incurred were reasonable and for necessary, contract-related work;

- ASI's personnel were competent to perform the needed work;

- ASI's subcontract modifications were appropriately executed;

- The intent of the 8 (a) program was being achieved and whether the ASI contract should have been extended beyond the first year, since the 8 (a) 55-percent SBA requirement was not being met;

- Costs and performance was being adequately reported and monitored; and

- Modifications to the ASI contract were timely definitized.

The renegotiated FFCA between DOE and EPA allows EPA to assess DOE penalties if deliverables are not met timely. In recognition of this provision in the FFCA, DOE entered into a settlement agreement with EPA on May 13, 1991. DOE agreed to deposit $\$ 100,000$ into EPA's super-fund account and invest another $\$ 150,000$ in new innovative projects to deal with hazardous waste in and around the Fernald Facility, because it had not met certain deadiines mandated by EPA in the FFCA. EPA and DOE were negotiating revised dates to comply with EPA standards at the time of this audit. 
PART III

MANAGEMENT AND AUDITOR COMMENTS

Award and Administration of the study

\section{Management's comments on Recommendations}

WMCO and the Fernald site office reviewed and commented on this report, and DOE Headquarters concurred on their comments. In its June 11, 1991, response to our draft report, DOE's Division of Eastern Area Programs, office of Environmental Restoration, stated: "overall, the Department endorses and supports the general conclusions made by the OIG's tentative findings."

This general concurrence notwithstanding, DOE did not concur with recommendation 1 to withdraw delegation of contract administration from WMCO. For the following reasons, DOE Headquarters believed that withdrawing the delegation would not be in DOE's best interest.

- Most of the report's concerns pertain to early years of the ASI contract.

- WMCO has assigned a new contract administrator and therefore has adequate management control and oversight over the ASI contract.

0

WMCO's management and operating contract will expire on March 31; 1992, and the Department plans to recompete it.

- The recompetition will incorporate the RI/FS functions into the new management and operating contract, thus negating the need for contract administration for the 8 (a) subcontract.

- DOE has a new contracting officer and a contract specialist administering the contract.

\section{Auditor's comments}

While the current and planned contract conditions at the Fernald Facility may preclude the need for reassigning contract administration responsibilities, the unclear roles of responsibility and authority that caused some of the reported conditions remain. Therefore, it is imperative that DOE's 
contract officer closely monitor WMCo's ASI contract administration during the remaining months of WMCO's current management and operating contract.

\section{Management Comments on Background, Observations, and Conclusions}

Management provided the following additional comments on the background, observations, and conclusions:

1. At the time of award it was DOE and SBA's position that ASI was technically qualified to perform the RI/FS work they were contractually hired to do. We did not know the total scope of work at the time of ASI's selection. The known work requirement at the time of selection seemed reasonable for ASI to perform and was in line with the purpose of the 8 (a) program.

However, as additional information was obtained about the environmental condition of the site arter ASI began their work, it became obvious that more reliance would have to be placed upon ASI's prime environmental subcontractor. The work has and is still being accomplished.

\section{Auditor's Comments}

A WMCO employee told us that they advised DOE not to award the contract to ASI because they were not technically qualified to perform the RI/FS. The scope of work defined in the contract consisted of 18 specific tasks that had to be performed to complete the RI/FS. Management's statement that the environmental conditions at the Fernald Facility became more evident after ASI began working supports the assertion that the scope of the work was not known and the original estimate of $\$ 1.7 \mathrm{million}$ to complete the RI/FS could not be accomplished.

2. When verbal concerns were expressed regarding major deliverables or ASI's performance, the contract files were documented by WMCO. The degree of documentation varied depending on concerns expressed by DOE relative to the need for ASI to continue the work and maintain the schedule. DOE's concerns were guided under pressure from the EPA to comply with the Federal Facility Compliance Agreement which later became the consent P.greement. 


\section{Auditor's Comments}

We did not find evidence that the contract files were documented regarding early technical problems related to deliverables of the workplan. The documentation of the inabilities of ASI to perform adequately could have been used as a basis to terminate the contract after the first year.

3. The WMCO Contract Administrator obtained review of the subject invoices prior to payment from wMCO technical representatives assigned to monitor ASI's daily activities, but prior to written concurrence by the FSO [Fernald site office] COR.

\section{Auditor's Comments}

This comment agrees with auditor's observations and conclusions.

4. The referenced personnel change occurred early in the contract term. ASI has since complied with all contract requirements with respect to key personnel as recognized on page 12 of the report.

\section{Auditor's comments}

This comment agrees with auditor's observations and conclusions.

5. Early in the contract term, DOE allowed ASI to modify lower-tier subcontracts without consent because they were evaluated as part of the prime contract negotiations. DOE has since instructed WMCO to invoke the subcontracting article of the contract that requires ASI to submit formal subcontract consent packages. Currently, ASI continues to submit procurement consent packages for all lower-tier subcontract actions.

\section{Auditor's Comments}

This comment agrees with auditor's observations and conclusions. 
6. During the course of this contract, ASI notified WMCO of concerns over their ability to comply with this requirement. WMCO recommended to the DOE CO to calculate the subcontractor utilization based on the total period of the contract and not by individual contract year. The DOE CO obtained approval from SBA to calculate subcontractor utilization in this manner. ASI currently meets the 55 percent requirement and is projected to do so through the expiration of the contract.

\section{Auditor's Comments}

SBA advised us that this requirement must be met on an annual basis. The CO did not provide evidence that SBA gave ASI an exemption from the requirement.

7. The reporting requirements in the contract required ASI to submit a cost management report utilizing a standard DOE form. In early 1990, more specific reporting requirements were defined by the COR and the WMCO technical representatives because the scope of work was better defined. A cost and schedule control reporting format was developed and ASI was directed to begin submitting reports under this more detailed structure. Page 15 of the OIG report recognizes that the revised reporting system provides and adequate basis to track performance.

\section{Auditor's Comments}

This statement agrees with auditors observations and conclusjions.

8. WMCO has already implemented a change in the approach of administering this contract which will minimize the amount of change orders required. The contract is not administered where ASI is obligated to provide a required level of effort for a predetermined period. This provides greater flexibility as current undefined work can be tasked within the available level of effort. Contract modifications will only be required for tasks that would increase the level of effort.

\section{Auditor's Comments}

The comments stated here do not address whether contract modifications will be definitized timely. 
9. The estimated cost of $\$ 1.7$ million was for the first year of the contract not the estimated value of the original period of performance ( 5 years).

\section{Auditor's comments}

Our review of the Request for Proposal indicated that the statement of work included 18 tasks on which ASI based its estimated cost to complete the work. Contract clause B.005 indicates that a level of effort contract was negotiated. At the same time, clause B.006 states that the work required under the contract will be completed as described in the statement of work (section C.001), which identifies the entire scope of work. The contract should have been written more clearly to identify the funding level of $\$ 1.7$ million to a specific time frame and specific scope of work. 
I. ...
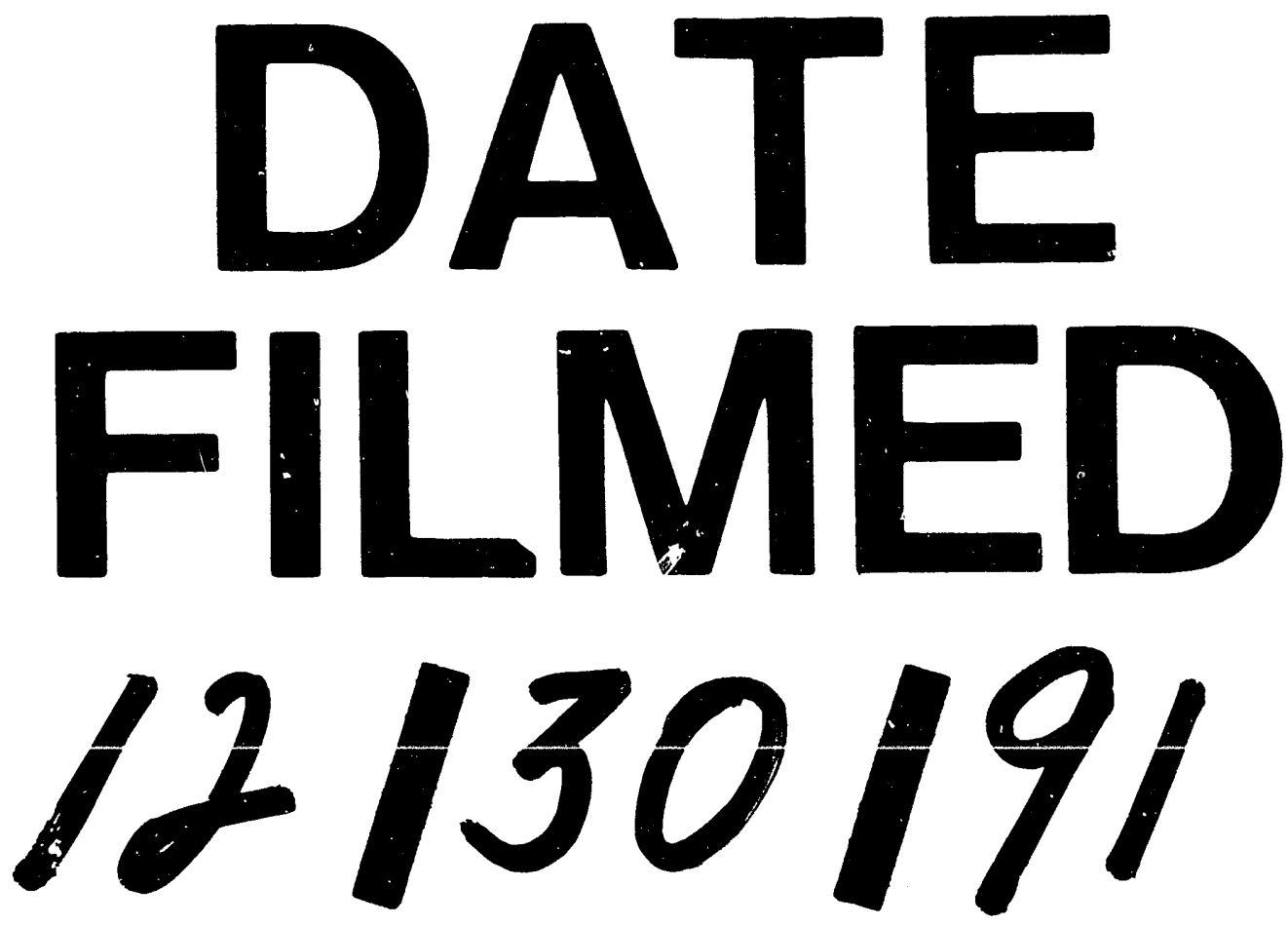

$T$ 
